\title{
Treatment of EVA with corona discharge to improve its adhesion to polychloroprene adhesive
}

\author{
ASUNCIÓN MARTÍNEZ-GARCÍA ${ }^{1}$, ANA SÁNCHEZ-RECHE ${ }^{1}$, \\ SANTIAGO GISBERT-SOLER ${ }^{1}$, CARMEN M. CEPEDA-JIMÉNEZ ${ }^{2}$, \\ ROSA TORREGROSA-MACIÁ ${ }^{2}$ and JOSÉ MIGUEL MARTÍN-MARTÍNEZ ${ }^{2, *}$ \\ ${ }^{1}$ AIJU (Toy Research Institute), Avda. Industria 23, 03440 Ibi, Alicante, Spain \\ ${ }^{2}$ Adhesion and Adhesives Laboratory, Department of Inorganic Chemistry, University of Alicante, \\ 03080 Alicante, Spain
}

Received in final form 30 September 2002

\begin{abstract}
Ethylene vinyl acetate (EVA) material containing $20 \mathrm{wt} \%$ vinyl acetate (EVA20) was treated with corona discharge to improve its adhesion to polychloroprene adhesive. Several experimental variables in the corona discharge treatment of EVA20 were considered: corona energy, type of electrode, and number of consecutive treatments. Advancing contact angle measurements (water, $25^{\circ} \mathrm{C}$ ) showed an increase in the wettability of EVA20 after treatment with corona discharge, which corresponds to an increase in the $\mathrm{O} / \mathrm{C}$ ratio on the treated surface. The higher the corona energy (i.e. the higher discharge power and longer treatment times), the greater the degree of surface oxidation. Peel strength values of the joints produced with EVA20 using a polychloroprene adhesive containing $5 \mathrm{wt} \%$ isocyanate increased from $1.5 \mathrm{kN} / \mathrm{m}$ (as-received EVA20) to $4.3 \mathrm{kN} / \mathrm{m}$ (corona-treated EVA20). A mixed (adhesional + cohesive in EVA20) locus of failure was obtained in all adhesive joints produced with corona discharge-treatedEVA20. Finally, the number of consecutive corona discharge treatments and the surface area of the electrode (spherical versus hook-shaped electrode) did not greatly influence the adhesion of EVA20 to polychloroprene adhesive.
\end{abstract}

Keywords: Corona discharge; surface treatment; EVA; polychloroprene adhesive; contact angle measurements; ATR-IR spectroscopy; SEM; T-peel strength.

\section{INTRODUCTION}

EVA (ethylene vinyl acetate) copolymers with vinyl acetate content up to $20 \mathrm{wt} \%$ are commonly used in the footwear and toy industries due to their good mechanical and aesthetic properties. In the toy industry, EVA materials are used to produce

\footnotetext{
*To whom correspondence should be addressed. Phone: 34-96-5903977. Fax: 34-96-5903454. E-mail: JM.Martin@ua.es
} 
puzzles, wheels for toy pushchairs and flexible toys. In the footwear industry, EVA soles are generally joined to leather uppers using adhesives. Because of the high polyethylene content in EVA, adhesion problems are commonly encountered due to its low surface energy. Surface modifications should be an adequate method to improve the wettability and adhesion of polyolefins, and the corona discharge treatment is one of the most commonly used treatments for polyethylene films $[1,2]$. This treatment is fast, can be easily adapted to industrial production, and produces an increase in adhesion [3].

Corona discharge treatment has been used to promote the adhesion of EVA films to aluminium in the packaging industry, and also to paper and other polymers [4-7]. There are some patents [6-10] showing the effectiveness of the corona discharge treatment for EVA films to membranes [6] or PET (poly(ethylene terephtalate)) films [7], for EVA laminates to paper [8], for EVA laminates in food packaging [9], and manufacturing of cups [10]. The increase in the surface energy of EVA facilitates its adhesion to different substrates or laminates generally under temperature and pressure. However, all the above literature deals with the improved adhesion of thin EVA films.

Thus, one of the objectives of this study was the improvement in the adhesion properties of a $2 \mathrm{~mm}$ thick EVA copolymer containing $20 \mathrm{wt} \%$ vinyl acetate (EVA20) to polychloroprene adhesive using corona discharge as surface treatment. This is a common adhesive joint used in the footwear industry to join EVA soles to leather uppers. Currently, application of a primer is necessary to improve the adhesion of EVA to leather using polychloroprene adhesive. This primer contains solvents, which are not desirable in the footwear industry. Therefore, in this study, we explored corona discharge as an alternative to the solvent-based primers in the joining of EVA.

On the other hand, considering that the effectiveness of the corona discharge treatment depends on different experimental parameters, so in this study, the effects of corona energy (modified by varying the length of treatment and/or the corona discharge power), the type of electrode and the number of consecutive treatments on the adhesion of EVA 20 were also considered.

\section{EXPERIMENTAL}

\subsection{Materials}

EVA containing $20 \mathrm{wt} \%$ vinyl acetate (EVA20) supplied by REPSOL QUÍMICA (Santander, Spain) was used in this study. The melt flow index of EVA20 is $3 \mathrm{~g} / 10 \mathrm{~min}$ and its Shore A and D hardnesses are 91 and 39, respectively (data supplied by REPSOL QUÍMICA [11]). The EVA polymer was received as pellets and moulded using a Margarit JSW injection machine to obtain test samples of $150 \mathrm{~mm}$ length, $60 \mathrm{~mm}$ width and $2 \mathrm{~mm}$ thickness. The following injection conditions were used: temperature $=170^{\circ} \mathrm{C}$; injection time $=6 \mathrm{~s}$; injection pressure $=$ 
$60 \%$ of total pressure $\left(1570 \mathrm{bar} ; 1 \mathrm{bar}=10^{5} \mathrm{~Pa}\right)$; mould temperature $=20^{\circ} \mathrm{C}$. The injection moulded pieces were cut into test samples of sizes $20 \times 30 \times 2 \mathrm{~mm}$ for characterization and $150 \times 30 \times 2 \mathrm{~mm}$ for adhesion tests.

Adhesive joints of treated EVA20 were made using a commercial two-component solvent-based polychloroprene adhesive consisting of polychloroprene adhesive itself (Telcopren 3003, supplied by Composan Adhesivos S.A., San Vicente del Raspeig, Spain) and $5 \mathrm{wt} \%$ isocyanate (Desmodur RF, provided by Bayer, Leverkusen, Germany). The adhesive and the isocyanate were mixed just before applying using a brush to two identically treated EVA20 strips. The adhesive was cured in open air for $1 \mathrm{~h}$ and afterwards melted at $100^{\circ} \mathrm{C}$ using an infrared lamp (to facilitate the interlocking of the chains of the adhesive). The two strips were then placed in contact and a pressure of $0.8 \mathrm{mPa}$ was applied for $10 \mathrm{~s}$ to achieve a suitable joint. The polychloroprene adhesive solution contained $25 \mathrm{wt} \%$ solids and its Brookfield viscosity was $3.0 \pm 0.2 \mathrm{Pas}$, as obtained following the procedure described in the following section. The thickness of the adhesive layer applied on EVA20 was about $100 \mu \mathrm{m}$.

\subsection{Experimental techniques}

2.2.1. Corona discharge equipment. A Tantec Corona Generator model HV09 was used to modify the EVA20; the output voltage was $13 \mathrm{kV}$ at $25 \mathrm{kHz}$. A scheme of the electrode arrangement of the corona discharge unit used in this study is given in Fig. 1. The distance between the upper electrode and the sample was adjusted to $1 \mathrm{~mm}$. The sample was located on the nylon counter electrode, which could be displaced at a controlled speed. A spherical and a hook-shaped electrodes were used, and the treatment was performed in air at atmospheric pressure. The discharge power was varied between 48 and $93 \mathrm{~W}$. $150 \mathrm{~mm}$ long EVA20 samples were passed under the electrode at different speeds of the nylon counter electrode $(0.36-11.3 \mathrm{~m} / \mathrm{min})$. The parameter used in this study to characterize the corona discharge was the corona energy, expressed in $\mathrm{J} / \mathrm{cm}^{2}$. The corona energy was obtained using the following equation:

$$
\text { Corona energy }=\frac{\text { Power }}{\text { Speed } \times \text { treatment length }} .
$$

On the other hand, the number of consecutive corona discharge treatments was varied between 1 and 5 . The corona energy used was $10.3 \mathrm{~J} / \mathrm{cm}^{2}$, the discharge power was $93 \mathrm{~W}$ and the speed of treatment was $0.36 \mathrm{~m} / \mathrm{min}$.

2.2.2. Adhesive viscosity determination. The viscosity of the adhesive was obtained using a Brookfield RVT-II viscosimeter. $100 \mathrm{ml}$ of adhesive solution were used, and the viscosity was obtained by using the spindle number 4 at $50 \mathrm{rpm}$.

2.2.3. Contact angle measurements. Contact angles on the treated EVA20 were measured at $25^{\circ} \mathrm{C}$ using a Ramé-Hart 100-0 equipment by placing $4 \mu 1$ drops of 


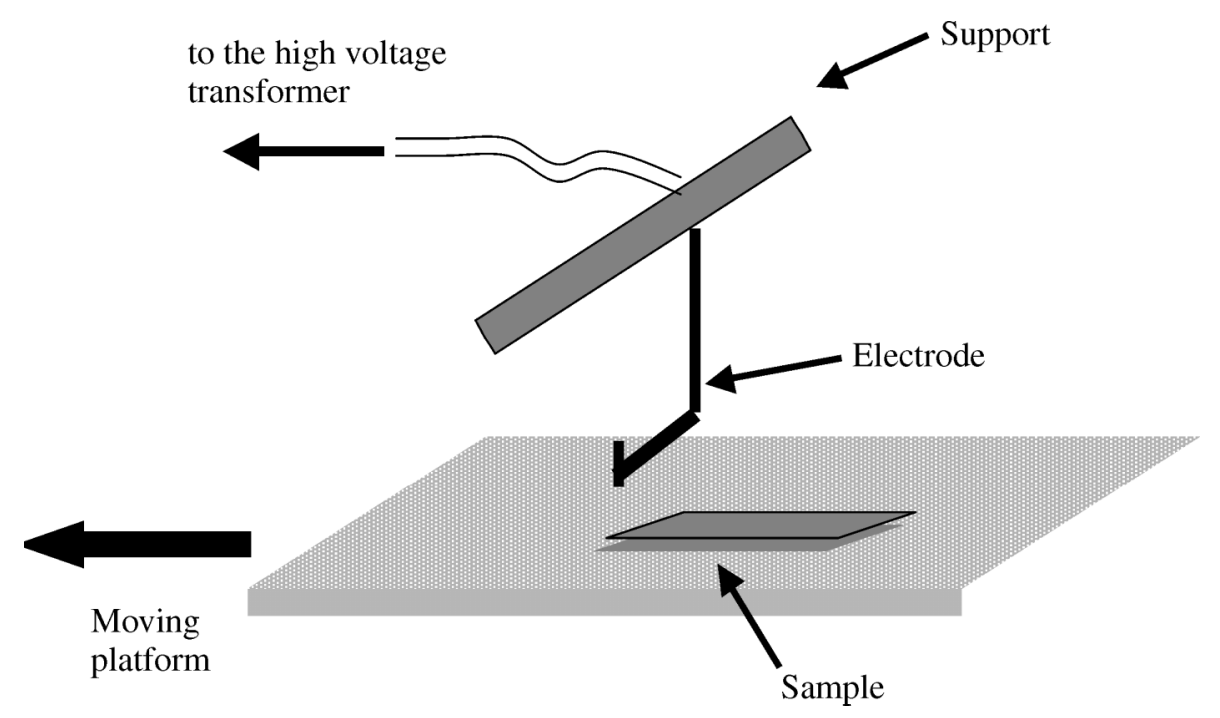

Figure 1. Scheme of the electrode arrangement of the corona discharge unit used in this study.

deionized and doubly distilled water on the surface. The samples were placed into a chamber saturated with water vapour at $25^{\circ} \mathrm{C}$, at least $15 \mathrm{~min}$ before the drop was placed on the EVA20 surface. The contact angle values were measured immediately after corona discharge treatment. The experimental error was \pm 2 degrees.

2.2.4. Infrared spectroscopy using ATR. ATR-IR spectra of corona dischargetreated EVA20, before and after T-peel tests, were obtained using a Nicolet FTIR 550 spectrometer. To avoid deep penetration of the IR radiation into the sample, the attenuated total multiple reflection method was employed using a KRS-5 (thallium bromo-iodide) crystal. The incident angle of the IR radiation was $45^{\circ}$. The resolution was $4 \mathrm{~cm}^{-1}$ and 100 scans were averaged.

2.2.5. X-ray photoelectron spectroscopy (XPS). XPS spectra of corona discharge treated EVA20 were obtained with a Vacuum Generator (VG) Scientific Microtech Multilab spectrometer, using $\mathrm{Mg} \mathrm{K}_{\alpha}$ radiation $(h v=1253.6 \mathrm{eV})$. X-ray source was operated at $15 \mathrm{keV}$ and $300 \mathrm{~W}$. The analyser was operated in the constant transmission mode. The pressure inside the analysis chamber was held below $5 \times 10^{-7}$ torr $\left(6.6 \times 10^{-5} \mathrm{~Pa}\right)$ during the course of the analysis. Samples were mounted onto the spectrometer probe with a double-sided tape. Rectangular sample pieces $(10 \mathrm{~mm} \times 20 \mathrm{~mm})$ were used, although the dimension of the analysis areas on the samples was $1 \mathrm{~mm} \times 3 \mathrm{~mm}$. The measurements were carried out at a takeoff angle of $45^{\circ}$. The spectrometer was calibrated for the $4 f_{7 / 2}$ photopeak of gold at $83.8 \mathrm{eV}$ and the $2 \mathrm{p}_{3 / 2}$ photopeak of copper at $932.4 \mathrm{eV}$. Survey scans were taken in the range of $0-1100 \mathrm{eV}$ and high-resolution scans were obtained on all significant peaks in the survey spectra. Binding energies of all photopeaks were referenced 
to the $\mathrm{C} 1 s$ photopeak position for $\mathrm{C}-\mathrm{C}$ and $\mathrm{C}-\mathrm{H}$ species at $285.0 \mathrm{eV}$. Multicomponent carbon $1 s$ photopeaks were curve fitted using a Gaussian function with a full-width-at-half maximum (FWHM) of $1.6 \pm 0.1 \mathrm{eV}$.

2.2.6. Scanning electron microscopy (SEM). SEM micrographs of the as-received and corona discharge treated EVA20 were obtained in a JEOL SEM J840 instrument using an electron beam energy of $20 \mathrm{kV}$. The samples were coated with gold.

2.2.7. T-peel strength measurements. The adhesion was evaluated from T-peel tests on treated EVA20/polychloroprene adhesive joints ( $72 \mathrm{~h}$ after bond formation) using an Instron 4011 instrument; a crosshead speed of $0.1 \mathrm{~m} / \mathrm{min}$ was used. Five replicates for each experimental variable were obtained and data were averaged with an error less than $\pm 0.5 \mathrm{kN} / \mathrm{m}$. In order to more precisely assess the loci of failure of the joints, the failed surfaces obtained after peel tests were analyzed using ATR-IR spectroscopy and SEM.

\section{RESULTS AND DISCUSSION}

Different experimental variables determine the effectiveness of the corona discharge treatment of EVA20. The effects of the corona energy during corona discharge experiments, the number of consecutive treatments, and the type of electrode were considered.

\subsection{Effect of corona energy}

Different corona energies (from 0.3 to $10.3 \mathrm{~J} / \mathrm{cm}^{2}$ ) were used in this study for treatment of EVA20, and were varied by varying the treatment time and the discharge power during treatment with corona discharge; a spherical electrode was used. Advancing and receding contact angles were measured using water as test liquid on different corona discharge-treated EVA20 samples. Figure 2a shows that the advancing contact angle values are higher than the receding ones and always the same differences are obtained for all corona discharge-treated EVA20 samples. The advancing contact angle values were used in this study to monitor the variations in wettability in all treated EVA20 as a function of the corona energy.

Figure $2 \mathrm{~b}$ shows the variation of the advancing contact angle values on the corona discharge treated EVA20 as a function of the corona energy. The water contact angle value on EVA20 decreases after corona discharge treatment for all the range of corona energy used in this study. The higher the corona energy, the lower the advancing contact angle value although the variation in contact angle values is relatively small (50-62 degrees). Therefore, the treatment with corona discharge increases the wettability of EVA20.

The ATR-IR spectra of some corona discharge-treated EVA20 samples are given in Fig. 3 as typical examples. The as-received EVA20 shows the typical bands of 


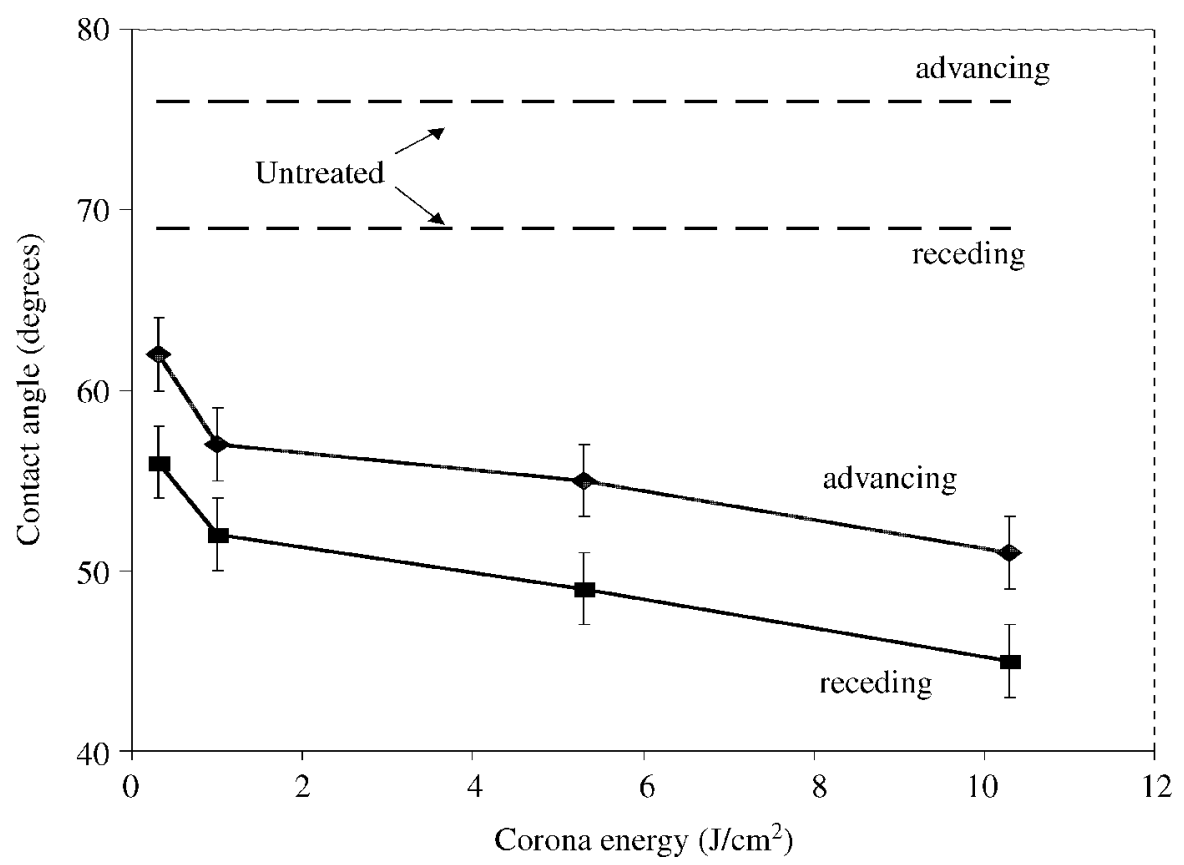

(a)

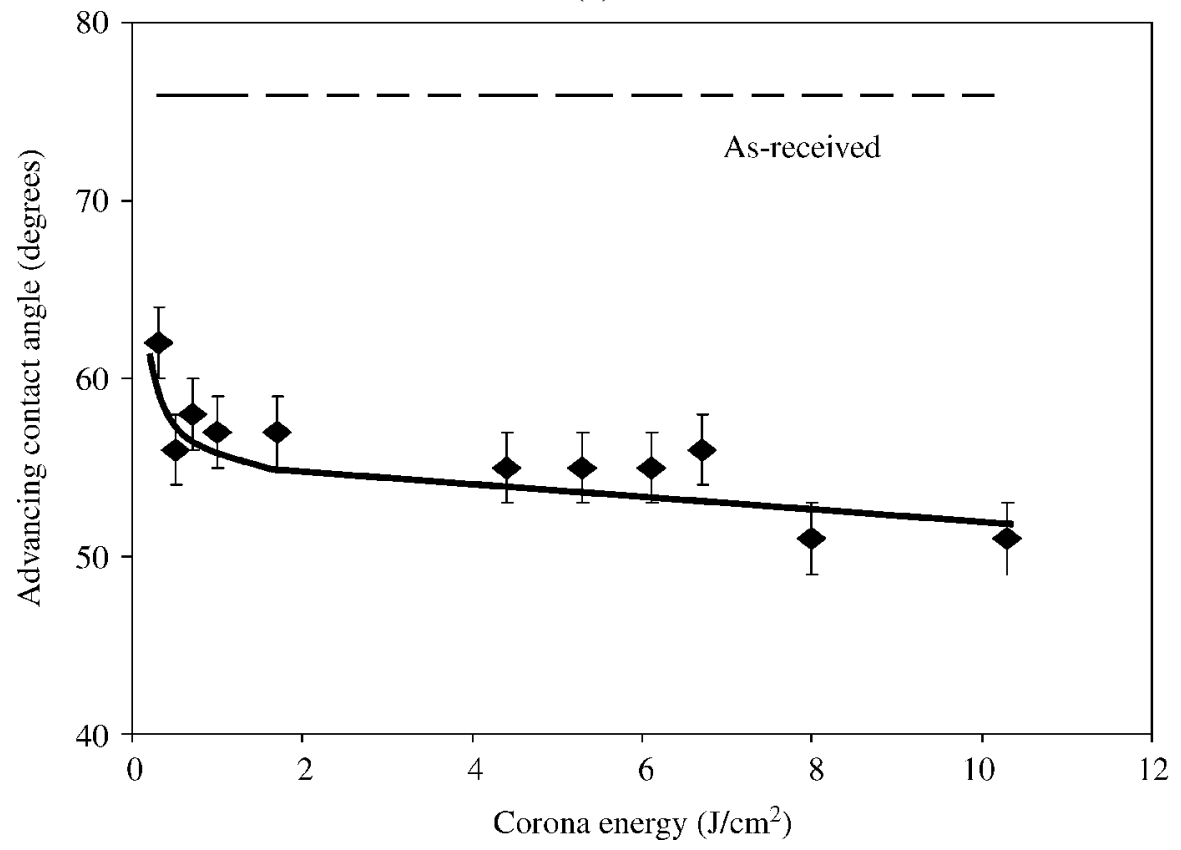

(b)

Figure 2. (a) Advancing and receding contact angle values (water, $25^{\circ} \mathrm{C}$ ) on some corona dischargetreated EVA20 as a function of the corona energy. Discharge power $=93 \mathrm{~W}$. (b) Advancing contact angle values (water, $25^{\circ} \mathrm{C}$ ) on corona discharge-treated EVA20 as a function of the corona energy. Discharge power $=48-93 \mathrm{~W}$; speed $=0.36-11.3 \mathrm{~m} / \mathrm{min}$. 


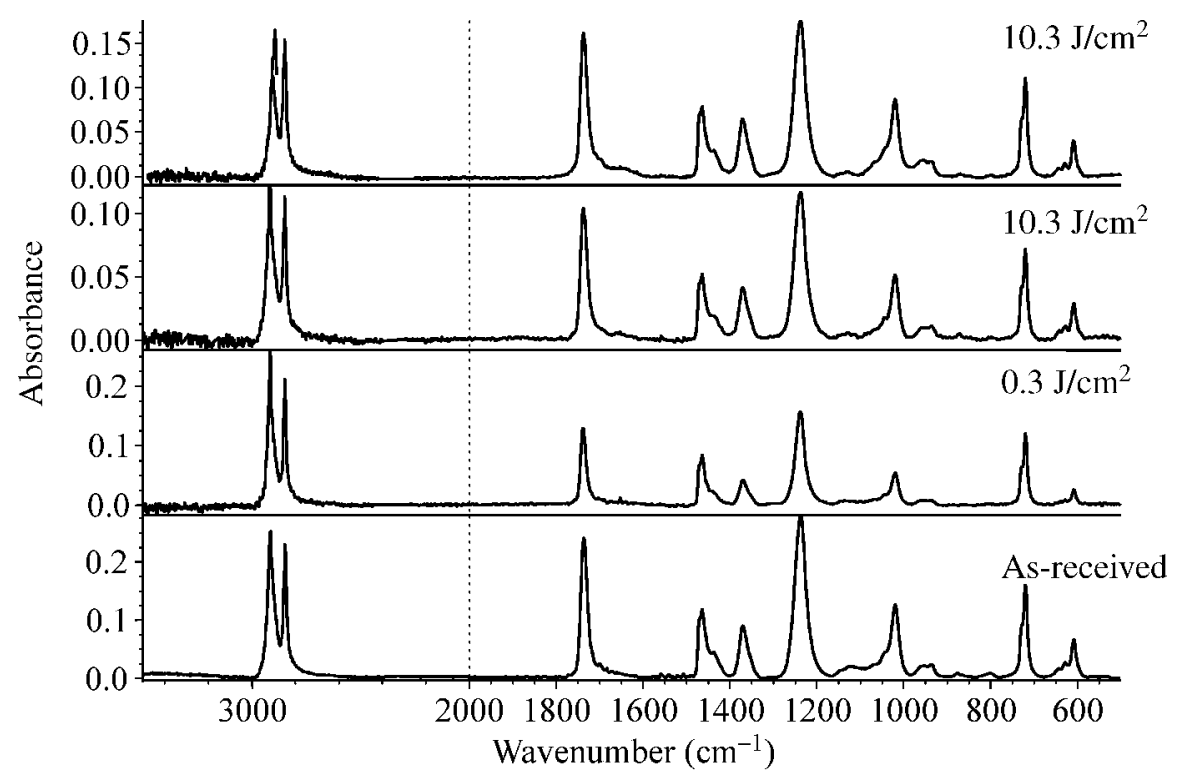

Figure 3. ATR-IR spectra of corona discharge treated EVA20 at different corona energies. Discharge power $=93 \mathrm{~W}$; speed $=0.36-11.3 \mathrm{~m} / \mathrm{min}$.

vinyl acetate $\left(1739,1025,1238\right.$ and $\left.608 \mathrm{~cm}^{-1}\right)$ and ethylene $(2847,2915,1370$, 1463 and $722 \mathrm{~cm}^{-1}$ ). The corona discharge treatment produces slight surface modifications mainly due to the formation of oxygen-containing moieties on the surface, which can be seen as a knee at $1655 \mathrm{~cm}^{-1}$. Only small differences are noticed by increasing the length of treatment, indicating that the modifications are produced in a thin external surface of EVA20. Therefore, XPS (a more sensitive surface analysis technique [12-14]) was used to assess the chemical modifications produced by the treatment.

Table 1 shows the elemental composition of the as-received and some corona discharge treated EVA20 obtained using XPS. The elemental composition of the asreceived EVA20 surface mainly corresponds to carbon and oxygen. Small amounts of nitrogen and silicon are also obtained which are most likely due to surface contamination. The percentage of oxygen is lower than expected for an EVA containing $20 \mathrm{wt} \%$ vinyl acetate, because the different chemical composition of the surface with respect to the bulk. Curve fitting of $\mathrm{C} 1 s$ photopeak (Fig. 4) shows the typical bands corresponding to EVA: $285 \mathrm{eV}(\mathrm{C}-\mathrm{H}, \mathrm{C}-\mathrm{C}), 285.7 \mathrm{eV}$ $\left(\mathrm{C}^{*} \mathrm{H}_{3}-(\mathrm{C}=\mathrm{O})-\mathrm{O}\right), 286.9 \mathrm{eV} \mathrm{HC} *-\mathrm{O}-(\mathrm{C}=\mathrm{O})-$, and $289.3 \mathrm{eV}\left(\mathrm{C}^{*}=\mathrm{O}\right)-\mathrm{O}$.

The corona discharge treatment produces a decrease in carbon and an increase in oxygen and in the $\mathrm{O} / \mathrm{C}$ ratio (Table 1 ). The increase in the corona energy during the treatment slightly decreases both the amount of oxygen-containing moieties on the EVA20 surface and the $\mathrm{O} / \mathrm{C}$ ratio. According to Fig. 4, the corona discharge creates new $\mathrm{C}=\mathrm{O}$ moieties (band at $288.0 \mathrm{eV}$ ) and the bands of vinyl acetate are also modified. However, quantification of these bands is not easy because of the overlap 
Table 1.

Elemental composition (atomic \%) of as-received and some corona discharge treated EVA20

\begin{tabular}{lcllc}
\hline Element & As-received & $\begin{array}{l}\text { Corona treated } \\
0.3 \mathrm{~J} / \mathrm{cm}^{2}\end{array}$ & $\begin{array}{l}\text { Corona treated } \\
5.3 \mathrm{~J} / \mathrm{cm}^{2}\end{array}$ & $\begin{array}{l}\text { Corona treated } \\
10.3 \mathrm{~J} / \mathrm{cm}^{2}\end{array}$ \\
\hline $\mathrm{C}$ & 85.4 & 75.8 & 78.3 & 79.2 \\
$\mathrm{O}$ & 13.1 & 21.3 & 19.9 & 19.5 \\
$\mathrm{~N}$ & 0.2 & 0.3 & 0.2 & 0.6 \\
$\mathrm{Si}$ & 1.3 & 2.6 & 1.6 & 0.7 \\
$\mathrm{O} / \mathrm{C}$ & 0.15 & 0.28 & 0.25 & 0.25 \\
\hline
\end{tabular}

of bands due to vinyl acetate and the new carbon-oxygen moieties created by the treatment. Therefore, the trend given in Fig. 4 will be used in this study to show that the corona discharge treatment introduces new oxygen-containing moieties on the EVA20 surface, which are responsible for the decrease in contact angle values (Fig. 2). Furthermore, the degree of oxidation increases by decreasing the corona energy during the treatment as noticed by the changes in the relative intensities of the bands given in Fig. 4. On the other hand, some nitrogen moieties are also created on the corona discharge treated EVA20 surface as a consequence of extended oxidation in air, in agreement with previous results for other polymers [15].

Because the lower contact angle values do not correspond to the higher atomic percentages of elements in the corona discharge-treated EVA20, additional contribution to contact angle values must be considered. In fact, the roughness of EVA20 was modified by corona discharge treatment. SEM micrographs (Fig. 5) show some cracks and heterogeneities on the surface of treated EVA20 in contrast to the rather smooth surface of the as-received material; the corona discharge treatment produces surface degradation in a non-uniform way. The modifications are more marked as the corona energy increases, indicating that surface ablation is favoured by increasing the corona energy which leads to the removal of the outermost copolymer surface.

As a consequence of chemical and morphological modifications on the EVA20 surface produced by treatment with corona discharge, improved adhesion in EVA20/ polychloroprene $+5 \mathrm{wt} \%$ isocyanate adhesive joints is achieved. The peel strength values obtained as a function of the corona energy are shown in Fig. 6. The asreceived EVA20/polychloroprene adhesive joint shows a low peel strength value due to the poor wettability and the non-polar nature of the as-received EVA20. Treatment with corona discharge increases the peel strength values by about $260 \%$, and this value is similar for corona energies higher than $1 \mathrm{~J} / \mathrm{cm}^{2}$. As a comparison, treatment of EVA20 with sulfuric acid (a chemical surface treatment) provides a peel strength value of about $3 \mathrm{kN} / \mathrm{m}$ which is slightly lower than the peel strength values obtained using corona discharge [16]; the adhesive used to produce the adhesive joints was the same as used in this study. 
$\mathrm{C} 1 s$
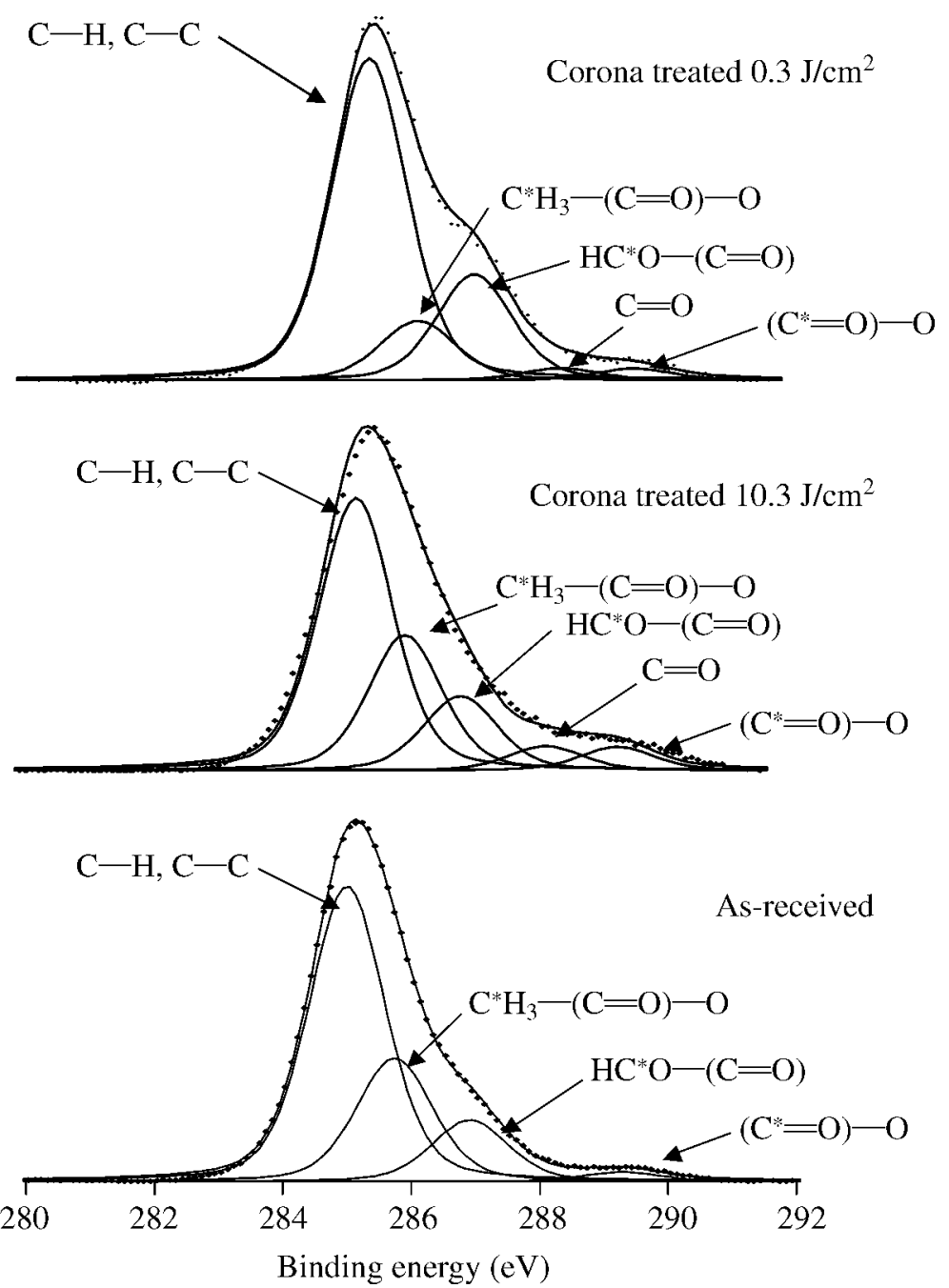

Figure 4. Carbon $1 s$ XPS spectra of as-received and corona discharge-treated EVA20 at different corona energies. Discharge power $=93 \mathrm{~W}$; speed $=0.36-11.3 \mathrm{~m} / \mathrm{min}$.

The trend in peel strength values as a function of the corona energy is not in full agreement with the variations in contact angle measurements, in surface chemistry and the ablation produced on the EVA20 surface by increasing the corona energy. Therefore, the loci of failure of the adhesive joints were assessed by characterization of the failed surfaces obtained after peel tests using ATR-IR spectroscopy and SEM. In this study, A surface corresponds to the failed surface that visually corresponds to the adhesive and P surface to that visually corresponding to the EVA20. The ATR-IR spectra of the adhesive and the as-received EVA20 (before adhesive joint 


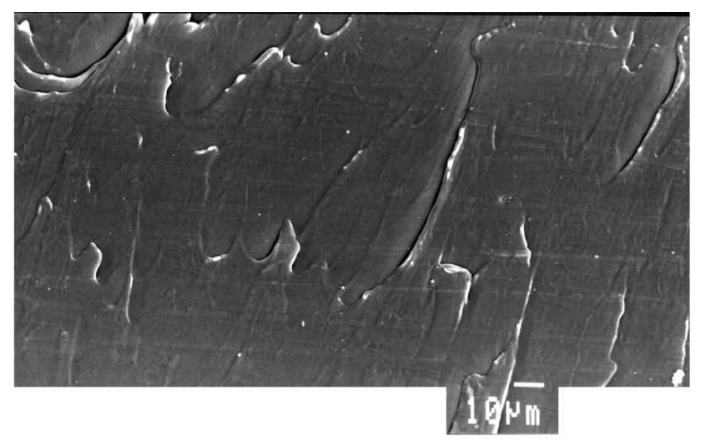

$10.3 \mathrm{~J} / \mathrm{cm}^{2}$

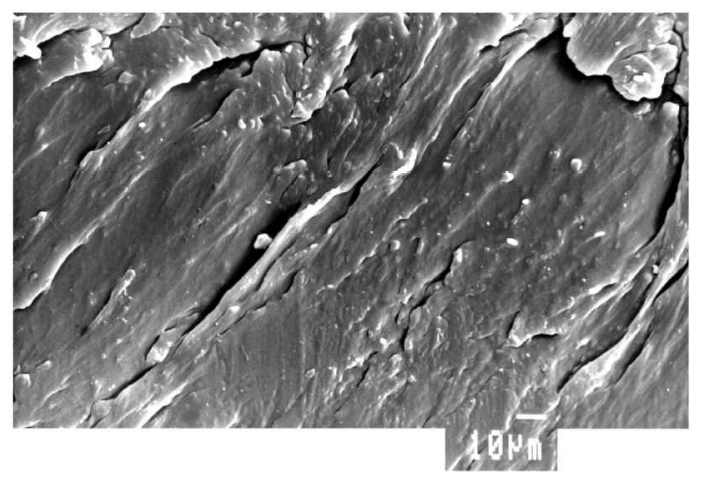

$1.0 \mathrm{~J} / \mathrm{cm}^{2}$

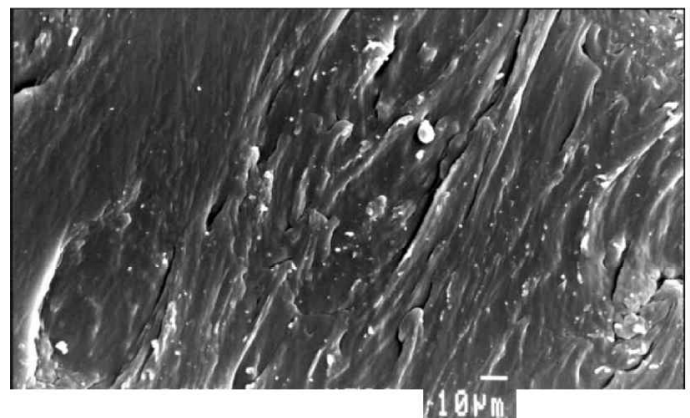

$0.3 \mathrm{~J} / \mathrm{cm}^{2}$

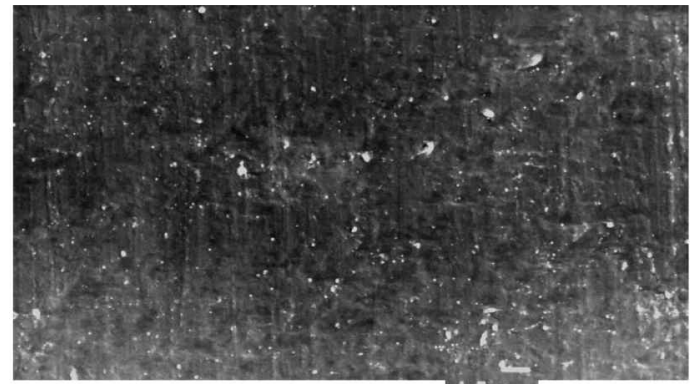

As-received

\section{$10 \mathrm{NI}$}

Figure 5. SEM micrographs of as-received and some corona discharge-treated EVA20 at different corona energies. Discharge power $=93 \mathrm{~W}$; speed $=0.36-11.3 \mathrm{~m} / \mathrm{min}$. 


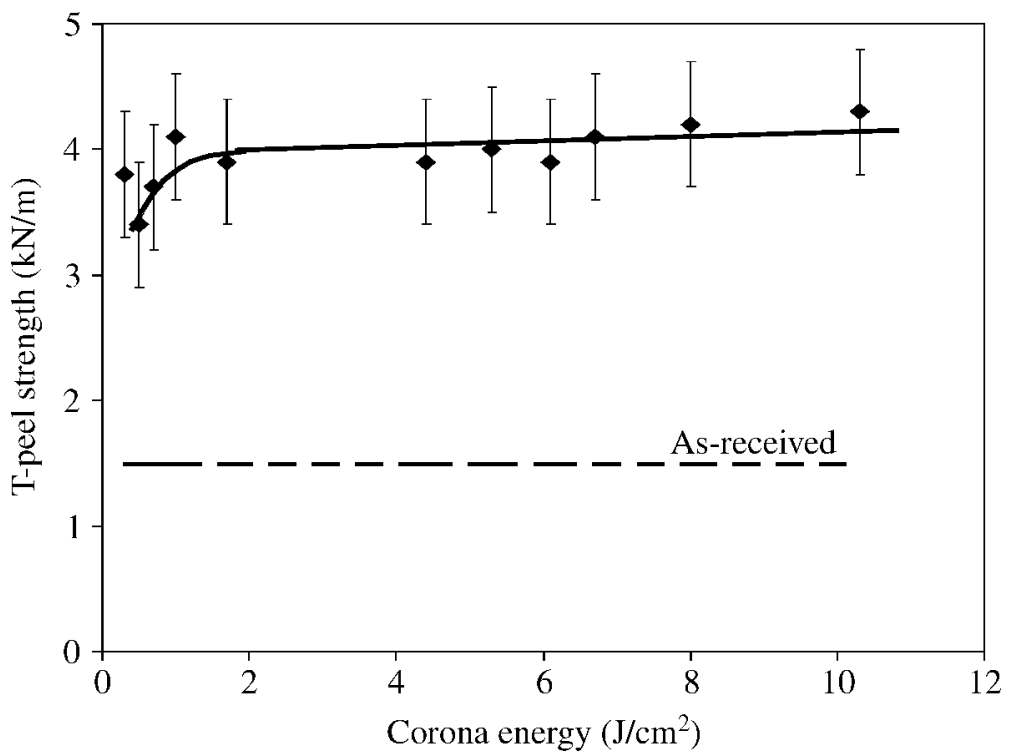

Figure 6. T-peel strength of as-received and corona discharge-treated EVA20/polychloroprene adhesive $+5 \mathrm{wt} \%$ isocyanate joints as a function of corona energy. Discharge power $=48-93 \mathrm{~W}$; speed $=0.36-11.3 \mathrm{~m} / \mathrm{min}$.

formation) are given in Fig. 7a. Different typical bands due to the adhesive and the EVA20 allow to differentiate their ATR-IR spectra and thus to assess the loci of failure of the adhesive joints. The intense bands at 1739 and $1238 \mathrm{~cm}^{-1}$ due to carbonyl group are typical of EVA20 and do not appear in the ATR-IR spectrum of the adhesive. On the other hand, the bands at 2268, 1521, 1184, 837, 799 and $699 \mathrm{~cm}^{-1}$ are typical of the adhesive.

For the adhesive joint produced with the as-received EVA20 (Fig. 7b), an adhesional failure was obtained, because the ATR-IR spectrum of the A surface is the same as that of the polychloroprene adhesive, and the ATR-IR spectrum of the P surface corresponds to the ATR-IR spectrum of EVA20. However, the SEM micrographs of the failed surfaces (Fig. 8a) show filaments of EVA20 on the A surface, probably caused by the swelling of the EVA20 surface by the solvent in the adhesive. The low molecular weight species on the swollen EVA surface facilitate the interaction with the adhesive under pressure during the fabrication of the joint.

The loci of failure of the corona discharge treated EVA20/polychloroprene adhesive joints are different. The ATR-IR spectra of the failed surfaces for the adhesive joint produced with EVA20 treated with $10.3 \mathrm{~J} / \mathrm{cm}^{2}$ are shown in Fig. 7c. Whereas the ATR-IR spectrum of P surface mainly corresponds to that of EVA20, the ATR-IR spectrum of the A surface shows a relatively reduced intensity of the bands due to the adhesive (Fig. 7a), and also several bands of EVA20 (C-O and $\mathrm{C}=\mathrm{O}$ bands at 1238 and $1739 \mathrm{~cm}^{-1} ; \mathrm{CH}_{2}$ and $\mathrm{CH}_{3}$ bands at 2847 and $2915 \mathrm{~cm}^{-1}$ ) appear, indicating that a mixed failure was obtained (adhesional + cohesive failure in EVA20). Therefore, during peel test some EVA20 is transferred to the adhesive 


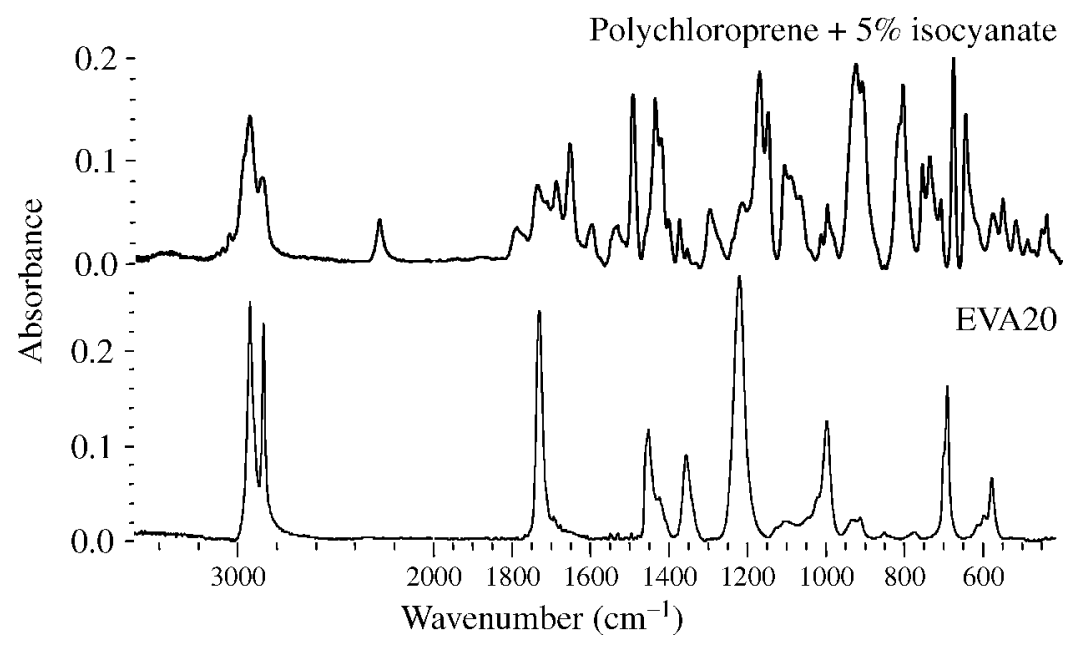

(a)

As-received EVA20/polychloroprene adhesive joint

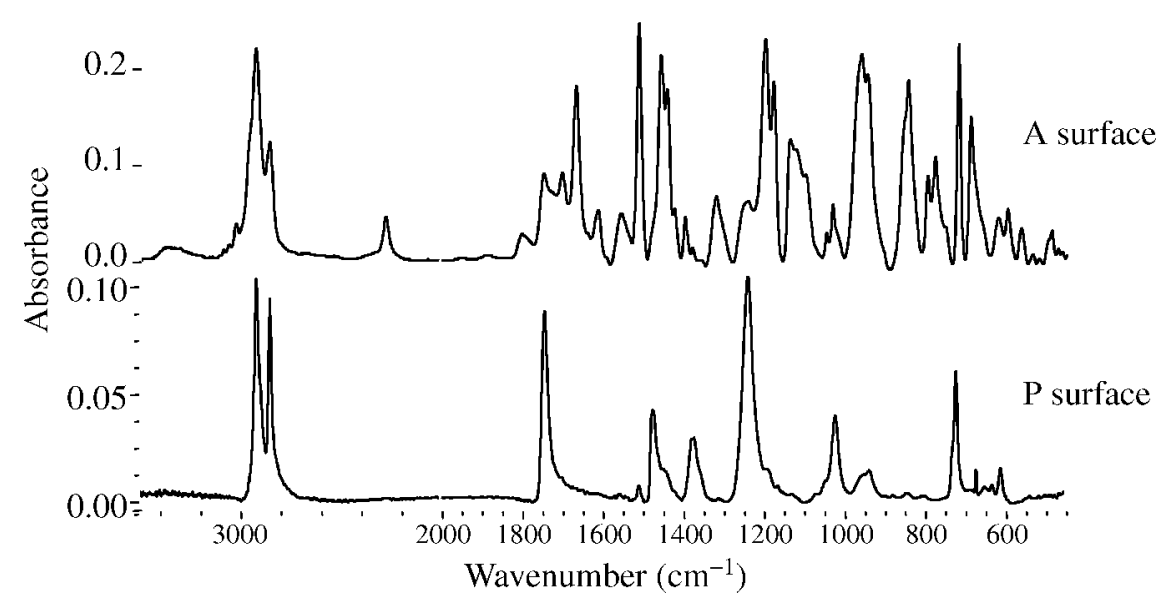

(b)

Figure 7. (a) ATR-IR spectra of as-received EVA20 and polychloroprene $+5 \mathrm{wt} \%$ isocyanate adhesive (before adhesive joint is produced). ATR-IR spectra of failed surfaces after peel tests on: (b) As-received EVA20/polychloroprene adhesive $+5 \mathrm{wt} \%$ isocyanate joint; (c) Corona discharge treated $\left(10.3 \mathrm{~J} / \mathrm{cm}^{2}\right)$ EVA20/polychloroprene $+5 \mathrm{wt} \%$ isocyanate adhesive joint; (d) Corona discharge treated $\left(0.3 \mathrm{~J} / \mathrm{cm}^{2}\right)$ EVA20/polychloroprene $+5 \mathrm{wt} \%$ isocyanate adhesive joint. A surface $=$ Failed surface that visually corresponds to the adhesive; P surface $=$ Failed surface that visually corresponds to the EVA20.

surface showing a partial cohesive failure in the EVA20. Furthermore, the SEM micrographs of the failed surfaces (Fig. 8b) show a more highly degraded P surface, indicating higher mechanical stresses produced during peel test. Consequently, the treatment with corona discharge improves the adhesion (as seen in the peel strength and the type of failure) of EVA20 to polychloroprene adhesive. 


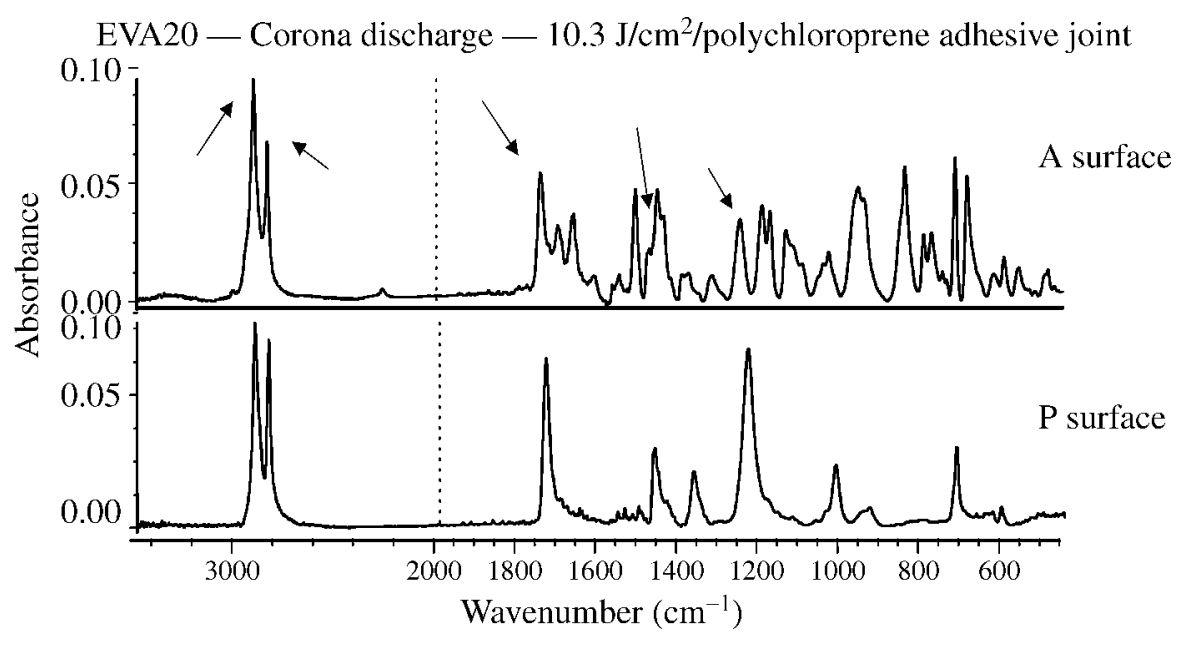

(c)

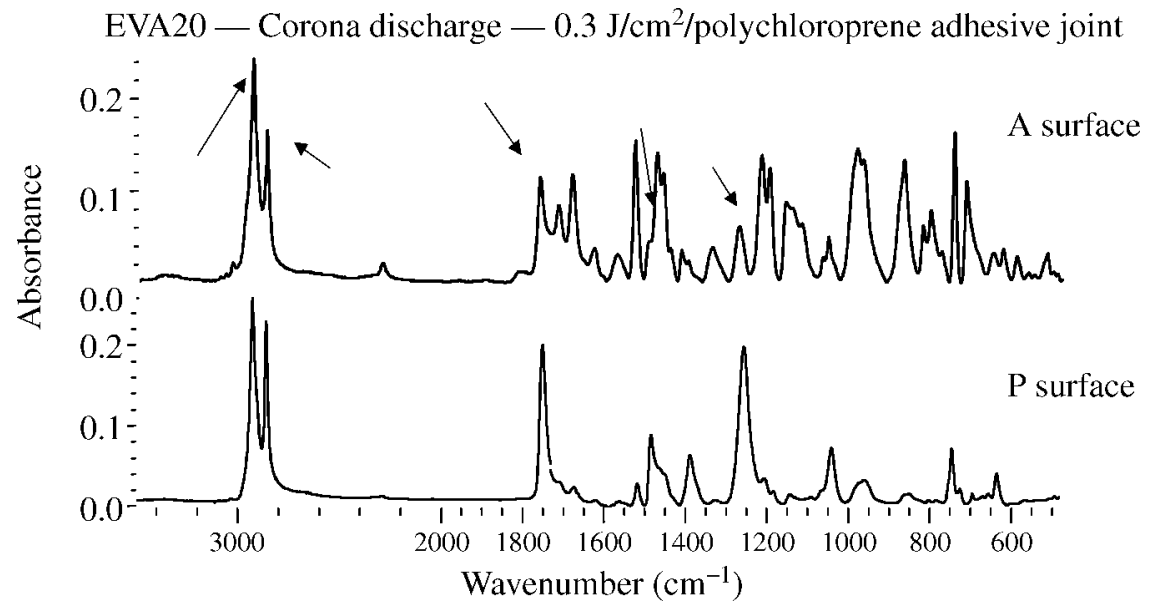

(d)

Figure 7. (Continued).

The corona energy also determines the loci of failure of the adhesive joints. In fact, the decrease in the corona energy to $0.3 \mathrm{~J} / \mathrm{cm}^{2}$ (Fig. 7d) produces a less cohesive failure in the EVA20 surface compared to that produced with $10.3 \mathrm{~J} / \mathrm{cm}^{2}$.

\subsection{Effect of the number of consecutive corona discharge treatments}

The effects of the number of consecutive corona discharge treatments (one to five) of EVA20 were assessed using a spherical electrode, setting the corona energy to $10.3 \mathrm{~J} / \mathrm{cm}^{2}$, the discharge power to $93 \mathrm{~W}$, and the treatment speed to $0.36 \mathrm{~m} / \mathrm{min}$. As the number of corona discharge treatments increases, the water contact angle value (Fig. 9) does not vary and is about 50 degrees; this value is lower than that on the as-received EVA20. The improved wettability of EVA20 treated with corona 
As-received EVA20/polychloroprene adhesive joint

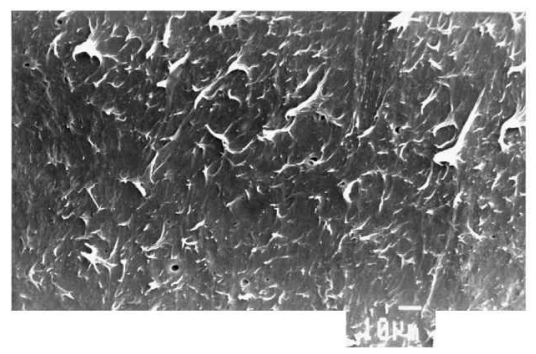

A surface

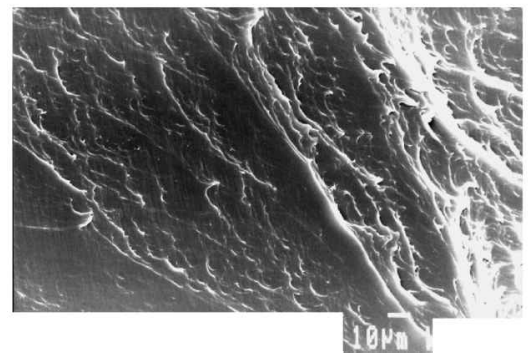

P surface

(a)

EVA20 - corona discharge: $10.3 \mathrm{~J} / \mathrm{cm}^{2} /$ polychloroprene adhesive joint

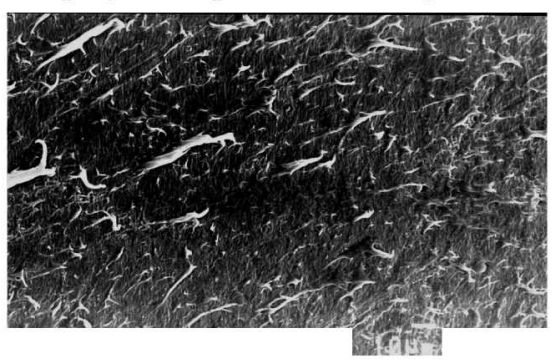

A surface

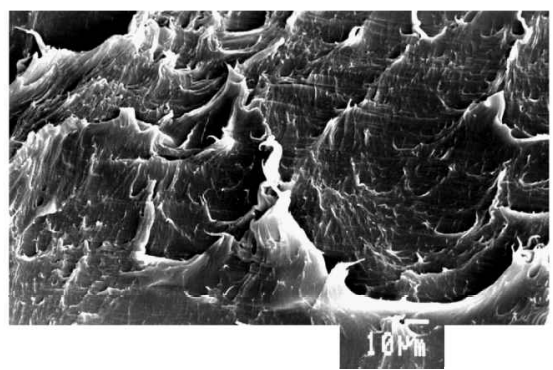

P surface

(b)

Figure 8. SEM micrographs of failed surfaces after peel tests on: (a) As-received EVA20/polychloroprene $+5 \mathrm{wt} \%$ isocyanate adhesive joint; (b) Corona discharge treated $\left(10.3 \mathrm{~J} / \mathrm{cm}^{2}\right)$ EVA20/polychloroprene $+5 \mathrm{wt} \%$ isocyanate adhesive joint. A surface $=$ Failed surface that visually corresponds to the adhesive; $\mathrm{P}$ surface $=$ Failed surface that visually corresponds to the EVA20. 


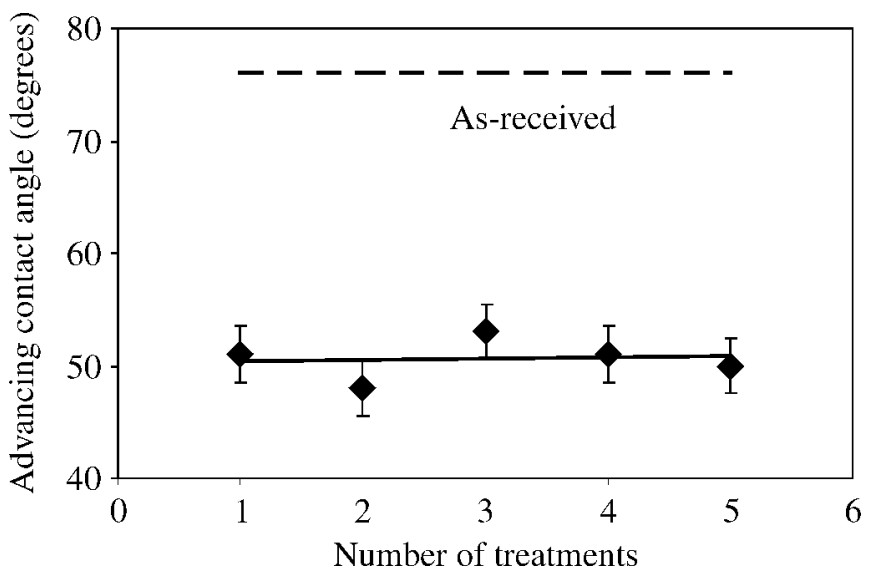

Figure 9. Contact angle values (water, $25^{\circ} \mathrm{C}$ ) on EVA20 as a function of the number of consecutive corona discharge treatments. Corona energy $=10.3 \mathrm{~J} / \mathrm{cm}^{2}$. Treatment speed $=0.36 \mathrm{~m} / \mathrm{min}$; discharge power $=93 \mathrm{~W}$.

\section{Table 2.}

Elemental composition (at \%) of as-received and EVA20 treated with a single corona discharge treatment and five consecutive treatments. Corona energy $=10.3 \mathrm{~J} / \mathrm{cm}^{2}$. Discharge power $=93 \mathrm{~W}$. Speed of treatment $=0.36 \mathrm{~m} / \mathrm{min}$

\begin{tabular}{lccc}
\hline Element & As-received & 1 treatment & 5 treatments \\
\hline $\mathrm{C}$ & 85.4 & 79.2 & 78.1 \\
$\mathrm{O}$ & 13.1 & 19.5 & 21.2 \\
$\mathrm{~N}$ & 0.2 & 0.6 & 0.3 \\
$\mathrm{Si}$ & 1.3 & 0.7 & 0.4 \\
$\mathrm{O} / \mathrm{C}$ & 0.15 & 0.25 & 0.27 \\
\hline
\end{tabular}

discharge can be ascribed to the decrease in carbon and increase in oxygen content on the treated EVA20 surface (Table 2). The increase in the number of consecutive corona discharge treatments produces only a slight increase in the $\mathrm{O} / \mathrm{C}$ ratio but somewhat higher increase in oxygenated functionalities. According to Fig. 10, the increase in the number of consecutive corona discharge treatments enhances more the creation of oxidized species, mainly $\mathrm{C}=\mathrm{O}$ (binding energy $=288.0 \mathrm{eV}$ ) and $\mathrm{R}-\mathrm{COO}^{-}(289.2 \mathrm{eV})$ moieties. On the other hand, the SEM micrographs (Fig. 11) show the formation of roughness and cracks on the treated EVA20 surface; the degree of roughness is increased by increasing the number of consecutive corona discharge treatments.

T-peel strength values of treated EVA20/polychloroprene adhesive joints (Fig. 12) are between 3.9 and $4.6 \mathrm{kN} / \mathrm{m}$ for one and five consecutive corona discharge treatments, respectively. Similarly, the loci of failure of the adhesive joints produced with EVA20 treated with one (Fig. 7c) and five (Fig. 13) consecutive corona discharge treatments are similar, i.e. a mixed failure (adhesional + cohesive failure 
$\mathrm{C} 1 s$
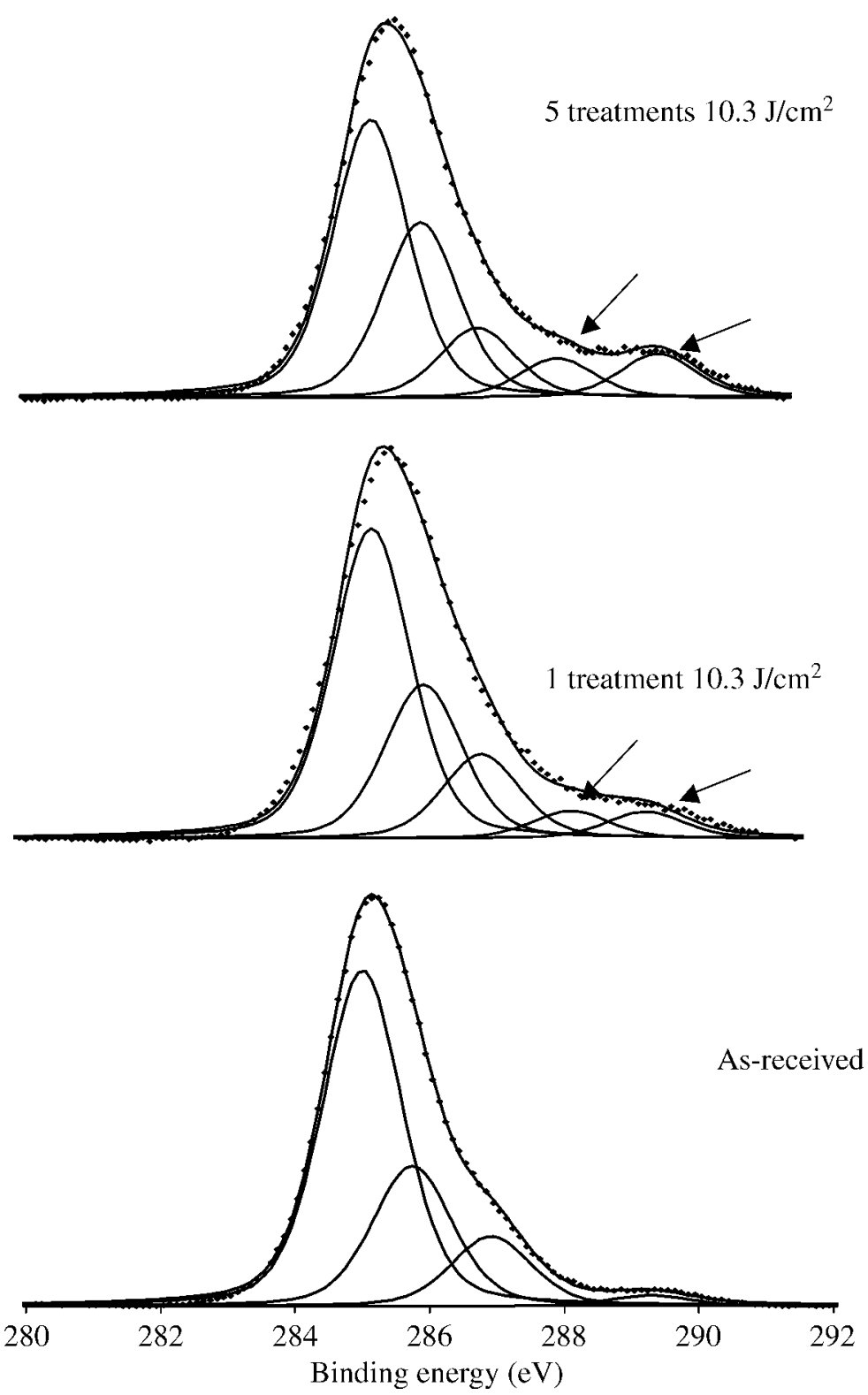

Figure 10. Carbon $1 s$ XPS spectra of as-received and EVA20 treated with 1 and 5 consecutive corona discharge treatments. Corona energy $=10.3 \mathrm{~J} / \mathrm{cm}^{2}$. Treatment speed $=0.36 \mathrm{~m} / \mathrm{min}$; discharge power $=93 \mathrm{~W}$.

in EVA20) is always obtained, predominantly cohesive in the EVA20. Therefore, the increase in the number of consecutive corona-discharge treatments does not significantly increase the adhesion of EVA20 to polychloroprene adhesive. 


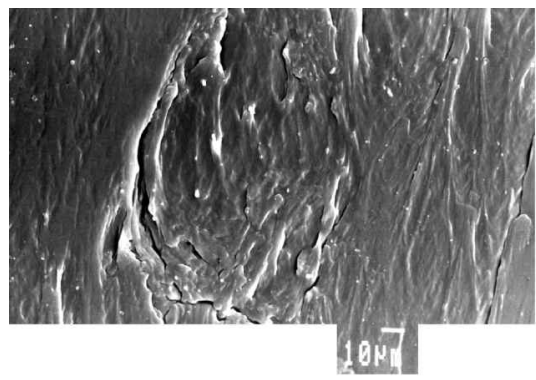

\section{2 treatments}

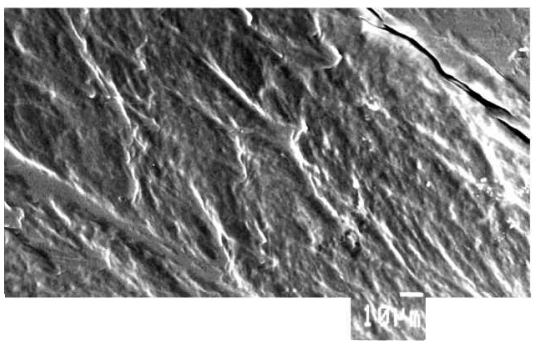

5 treatments

Figure 11. SEM micrographs of EVA20 treated with 2 and 5 consecutive corona discharge treatments. Corona energy $=10.3 \mathrm{~J} / \mathrm{cm}^{2}$. Treatment speed $=0.36 \mathrm{~m} / \mathrm{min}$; discharge power $=93 \mathrm{~W}$.

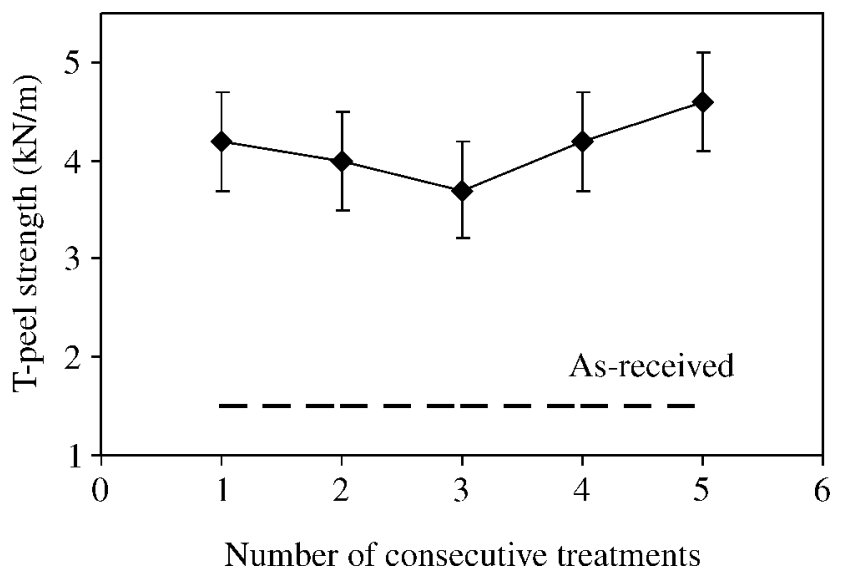

Figure 12. T-peel strength of corona discharge treated EVA20/polychloroprene $+5 \mathrm{wt} \%$ isocyanate adhesive joints showing the influence of the number of consecutive corona discharge treatments. Corona energy $=10.3 \mathrm{~J} / \mathrm{cm}^{2}$. Treatment speed $=0.36 \mathrm{~m} / \mathrm{min}$; discharge power $=93 \mathrm{~W}$.

\subsection{Influence of the type of electrode}

The type of electrode used in the corona discharge treatment determines the effectiveness of the treatment [3]. Therefore, two electrodes with different surface areas (one spherical and other hook-shaped) were used in this study. The corona energy was set to $10.3 \mathrm{~J} / \mathrm{cm}^{2}$, the discharge power to $93 \mathrm{~W}$, and the treatment speed to $0.36 \mathrm{~m} / \mathrm{min}$. 
EVA20 - Corona discharge $10.3 \mathrm{~J} / \mathrm{cm}^{2}-5$ treatments/polychloroprene adhesive joint

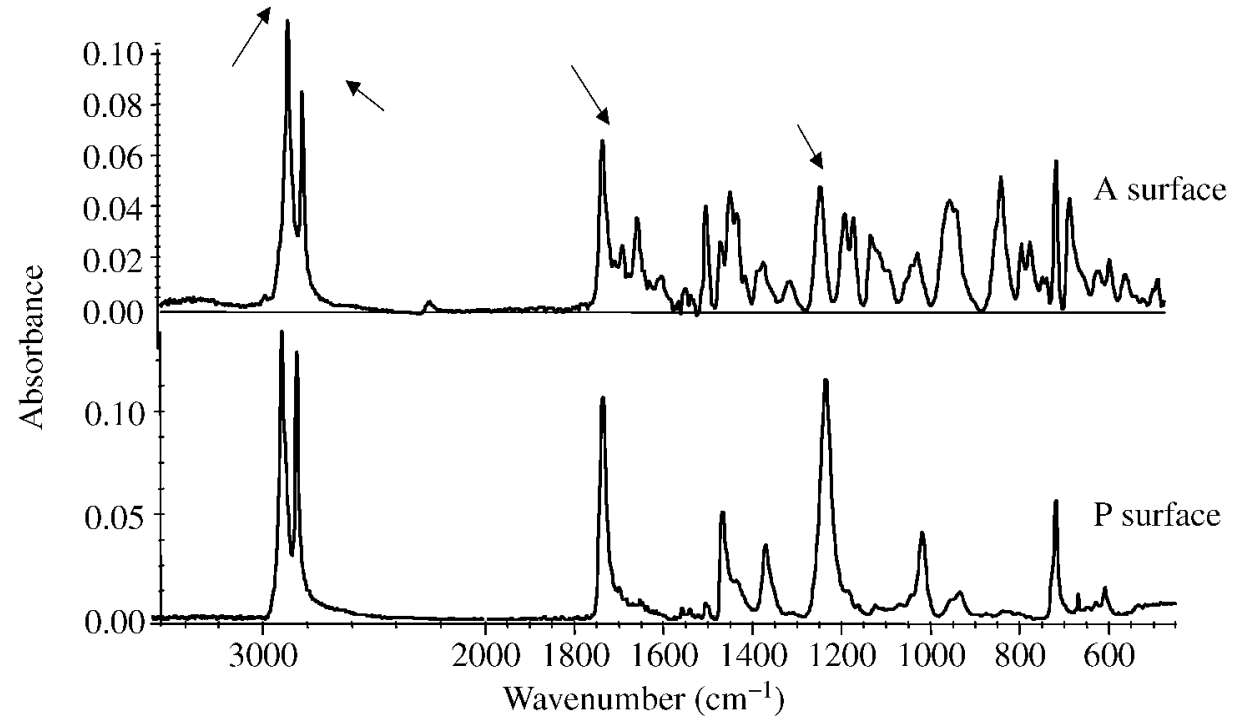

Figure 13. ATR-IR spectra of failed surfaces of five consecutive corona discharge treated EVA20/polychloroprene $+5 \mathrm{wt} \%$ isocyanate adhesive joints. Corona energy $=10.3 \mathrm{~J} / \mathrm{cm}^{2}$. Treatment speed $=0.36 \mathrm{~m} / \mathrm{min}$; discharge power $=93 \mathrm{~W}$. A surface $=$ Failed surface that visually corresponds to the adhesive; $\mathrm{P}$ surface $=$ Failed surface that visually corresponds to the EVA20.

The advancing contact angle values (water, $25^{\circ} \mathrm{C}$ ) on the EVA20 surface were similar using the two electrodes: 42 degrees for the spherical electrode and 40 degrees for the hook-shaped electrode. Also, chemical compositions and surface morphology were similar (not shown here). The T-peel strength value of corona discharge treated EVA20 was $4.3 \mathrm{kN} / \mathrm{m}$ for the spherical electrode and $4.0 \mathrm{kN} / \mathrm{m}$ for the hook-shaped electrode. Thus, the surface area and shape of the electrode used to generate the corona discharge do not affect the adhesion of EVA20 to polychoroprene adhesive.

\section{CONCLUSIONS}

The treatment with corona discharge increases the adhesion of EVA20 to polychloroprene adhesive due to the creation of surface roughness and the formation of $\mathrm{C}=\mathrm{O}$ and $\mathrm{RCOO}^{-}$moieties.

A single corona discharge treatment is enough to improve the adhesion of EVA20, and the surface area and geometry of the electrode neither greatly affect the degree of surface modification, nor the adhesion properties. The higher the corona energy, the greater the degree of surface modification on EVA20 surface. Similar peel strength values of corona discharge-treated EVA20/polychloroprene adhesive joints were obtained for treatment with corona energies higher than $1 \mathrm{~J} / \mathrm{cm}^{2}$. All joints 
produced with treated EVA20 show a mixed failure mode, mainly cohesive in the EVA20.

\section{REFERENCES}

1. M. Strobel, C. Dunatov, J. M. Strobel, C. S. Lyons, S. J. Perron and M. C. Morgen, J. Adhesion Sci. Technol. 3, 321 (1989).

2. K. L. Mittal (Ed.), Polymer Surface Modification: Relevance to Adhesion. VSP, Utrecht (1996).

3. S. Mannar Mannan and A. K. Mehta, Popular Plastics and Packaging (November), 53 (1991) .

4. T. Chihani, P. Bergmark and P. Flodin, J. Adhesion Sci. Technol. 7, 327 (1993).

5. K. Grundke, H. J. Jacobasch, St. Schneider and F. Simon, in: Proceedings of EURADH '94, Mulhousem, France, p. 373 (1994).

6. S. M. Nakamoto, M. F. Yoshida, M. Nakamizo and M. Yoshida, Patent DE 4117411, Japan (1991).

7. Mitsubishi Petrochem. Patent JP 32272236, Japan (1991).

8. Jujo Central, Patent JP 63153132, Japan (1988).

9. Toyo Ink Mfg, Patent JP 60260334, Japan (1985).

10. Toppan Printing, Patent JP 59093632, Japan (1984).

11. Technical Information, Copolímero EVA Alcudia. Repsol Química, Madrid (1993).

12. H. F. Webster and J. P. Wightman, J. Adhesion Sci. Technol. 5, 93 (1991).

13. T. Hjertberg, B. A. Sultan and E. M. Sorvik, J. Appl. Polym. Sci. 37, 1183 (1989).

14. M. Charbonnier, M. Romand, M. Alami and T. M. Duc, in: Polymer Surface Modification: Relevance to Adhesion, K. L. Mittal (Ed.), Vol. 2, p. 3. VSP, Utrecht (2000).

15. J. Comyn, L. Mascia and G. Xiao, Int. J. Adhesion Adhesives 16, 301 (1996).

16. A. Martínez-García, A. Sánchez-Reche and J. M. Martín-Martínez, J. Adhesion (in press). 